\title{
An Examination of the Impact of Peer Mentoring on First-Generation College Student Peer Mentors' Development of the Five Practices of Exemplary Leaders
}

\section{Abstract}

The purpose of this study was to examine how undergraduate peer mentors at Texas A\&M University perceive their development of leadership behaviors through their peer mentor experience. Participants were firstgeneration college students serving as mentors to first-generation college students at Texas A\&M University. A qualitative approach was used to examine reflections from the peer mentors about their personal best leadership experiences as a peer mentor and their self-reported highest scored practice on the Student Leadership Practices Inventory (SLPI). This study is rooted in Kouzes and Posner's $(1987,2002)$ Five Practices of Exemplary Leadership model. There were 33 peer mentors who participated in this study. Mentor reflections showed evidence of behaviors demonstrating all five of the exemplary leadership practices through serving as a peer mentor.

\section{Introduction \& Background}

Leadership development has become an integral process of the overall educational programming for students (Posner, 2012). With the enhanced focus and call for more high-impact experiences at all institutions of higher education along with institutions emphasizing leadership in their mission statements (Astin and Astin, 2000; Council for the Advancement of Standards in Higher Education, 2015), there appear to be ample opportunities for students to develop as leaders. From participating in a student-led organization, holding a position of leadership in an organization, participating on a sports team, volunteering, engaging in open discussions with students of different backgrounds (ethnic groups, socio-economic class, religion, etc.), identifying and engaging with a mentor (Dugan \& Komives, 2007), participating in learning communities (Bower \& Inkelas, 2010), and even through study abroad, students are at no loss for experiences that can help them grow and develop as leaders. We also know students who practice leadership and engage frequently in leadership behaviors and actions are rated as more effective leaders (Posner, 2012). While many opportunities exist for students to practice their leadership, there is still room for examining the design and specific activities within some of the more complex leadership experiences to understand which components are essential to facilitate the leadership development of students. Serving as a peer mentor is one of these experiences.

At Texas A\&M University, approximately $25 \%$ of the student population are first-generation college students (Texas A\&M University, n.d.). To aid in increasing the retention rate of this at-risk population, a learning community at a four-year, tier one, public institution was created. Peer mentors are an integral 
part of this learning community as they serve to assist freshman students to assimilate into the culture and community at the university. As part of their role, peer mentors assume leadership roles that allow them opportunities to develop leadership skills and learn valuable leadership lessons. Peer mentors are serving a need in helping their fellow peers succeed at a university, and in this process the peer mentors are developing as leaders themselves. While many experiences may purport to help students develop leadership, the nuances of how this is developed have not been well documented and need more examination by research scholars (Dugan \& Komives, 2007). In this paper, we explore how students who are peer mentors for a Freshman Success Program (FSP) perceive their development of leadership through the experience.

\section{Literature Review}

\section{Mentoring}

The role of mentor can emerge from many different roles in higher education such as faculty, student affairs educators, employers, and peers (Parks, 2000). Mentoring has been found to positively influence others in developing leadership, including the development of socially responsible leadership (Campbell et al., 2012; Collins-Shapiro, 2006; Dugan \& Komives, 2007; Dugan \& Komives, 2010; Hastings et al., 2015; Hastings \& Sunderman, 2019; Komives \& Collins-Shapiro, 2006; Komives et al., 2009). Peer mentoring has even been shown to fill in the gaps of faculty mentoring by impacting leadership values of commitment and collaboration from the socially responsible leadership model (Dugan \& Komives, 2007; Dugan \& Komives, 2010). Peer mentoring typically consists of an individual with experience and/or success in an area, the mentor, assisting a less experienced individual, the mentee. The role of a peer mentor is, therefore, an opportunity to lead and guide mentees. Thus, in a collegiate setting, peer mentoring is an experience that allows more advanced or experienced undergraduate students the opportunity for personal growth through the development of their leadership skills. Peer mentors can play a role in impacting an individual's leadership values, especially values of citizenship, commitment and collaboration (Dugan \& Komives, 2007; Dugan \& Komives, 2010).

Dugan and Komives (2007) identified mentoring relationships as one way to enrich campus leadership programs. They recommended developing processes for students to receive one-on-one attention in the college environment. The development of peerbased mentorships is a viable option for providing experienced undergraduate students the opportunity to lead by mentoring less experienced peers. Colvin and Ashman's (2010) study on peer mentoring relationships in higher education provided an indepth look at the benefits and risks of peer mentoring relationships in undergraduate students: "In general, both peer mentors and students saw benefits, ranging from individual gains to helping students become connected to the campus as a whole" (p. 131).

The influence of mentoring on college students' leadership development has been shown to have positive effects (Campbell et al., 2012; Connolly, 2017). The mentor-mentee interaction encourages and supports personal growth and development for both the mentee and the mentor (Colvin \& Ashman, 2010). Komives et al. (2005) acknowledged the contribution of peer mentors to college students' leadership identity development.

Leadership Development through Peer

Mentoring

When compared to college students who do not mentor, college students who do mentor have been reported to have higher generativity scores (Hastings et al., 2015) and significantly higher capacity to engage in socially responsible leadership (Barnes, 
2014). Hastings and Sunderman (2019) found that peer mentors perceive growth in generativity and PsyCap as a result of mentoring younger students for leadership development. Generativity is of interest because it has emerged as the strongest predictor of socially responsible leadership (Rossi, 2001). Lee et al. (2020) explored how peer mentors experienced growth in leadership outcomes. Of particular note was that mentors need education and training to realize their development and growth in leadership. Connolly (2017) documented perceptions of firstgeneration college students serving as peer mentors, specifically as resident advisors, related to the development of leadership skills as a result of their peer mentor experience. Connolly (2017) concluded peer mentoring experiences can be beneficial for first-generation college students as the peer mentors in their study were able to describe growth in personal leadership skills as a result of serving as a peer mentor.

"A great need exists to understand better the unique nature of college student leadership development as well as how the college experience contributes to that process" (Dugan \& Komives, 2007, p. 7). As leadership educators, it is important that we simply not just be aware that experiences can develop leaders, but we also must know how to specifically design experiences so students can maximize their leadership potential. In this study, we examined the perspectives of peer mentors and what they perceived to be the specific activities in their role as a peer mentor that contributed to their leadership growth and development.

\section{Theoretical \& Conceptual Framework}

Transformative Leadership and the Five Practices of Exemplary Leadership Model

Kouzes and Posner's (1987, 2002) Five Practices of Exemplary Leadership model (hereafter referred to as the "five practices") is rooted in the theory of transformational leadership. As the name implies, transformational leadership is a process that changes and transforms people (Northouse, 2013). The five practices model is a prescriptive model emphasizing behaviors individuals need to perform to become effective leaders, and the model has been used extensively with college students. We utilized this model as a framework for examining how the peer mentors in the FSP developed their leadership through their experience as a peer mentor. Kouzes and Posner found leaders demonstrated similar behaviors in their reflections about leadership experiences that constituted a time when they were at their best as a leader. These behaviors became known as the five practices (Kouzes \& Posner, 1987, 2002).

Student leadership behaviors can be measured by examining the frequency of leadership behaviors being used. Kouzes and Posner's (2018) Student Leadership Practices Inventory (SLPI) is "a leadership development tool" that enables students to identify those leadership practices they most often use. The SLPI provides a measure of how frequently students use the five practices. This instrument has been used extensively with college students and not just individuals already in the workforce. According to Posner (2012), "The more student leaders reported having both opportunities to be leaders and to develop their leadership skills the more they engaged in each of the five leadership practices" (p. 232). The five practices are model the way, inspire a shared vision, challenge the process, enable others to act, and encourage the heart (Kouzes \& Posner, 2018).

The practice of model the way means leaders must model the behaviors they expect of others. Specific actions within this practice include that a leader clarifies their values, affirms the shared values of the organization, and then aligns their actions with those shared values (Kouzes \& Posner, 2018). Inspire a shared vision refers to specific actions of leaders toward imagining and creating highly attractive futures for themselves and others. A leader does this by envisioning the future and then enlisting others in this vision by appealing to shared aspirations. Expressing enthusiasm and excitement for the vision can ignite passion for the vision in others (Kouzes \& 
Posner, 2018). Leaders who challenge the process overcome adversity and embrace opportunities to get better. Leaders who challenge the process value innovation and search for opportunities by looking outward for ways to improve. To challenge the process, leaders do have to experiment and take risks but also generate small wins and learn from experience (Kouzes \& Posner, 2018). The practice of enable others to act involves a recognition that achieving greatness requires the collaboration of a team and is based on trust and building relationships. Leaders can enable others to act by increasing their self-determination and developing competence in others. This practice is really about how leaders build future leaders (Kouzes \& Posner, 2018). Encouraging the heart involves a recognition that people can get exhausted, frustrated, and sometimes want to give up. When a leader steps in to recognize contributions and shows appreciation for individual excellence, people will stay motivated and likely keep performing. This practice consists of celebrating values and victories by creating a spirit of community and these recognitions and celebrations should be personal and personalized (Kouzes \& Posner, 2018).

\section{Context for the Study}

Peer mentors have the opportunity to practice and demonstrate these leadership practices through their involvement in the FSP. At Texas A\&M University, FSP is a learning community created to assist freshmen FSP scholars who are first-generation college students with their transition into college life. The FSP is overseen by a program coordinator who manages the members of the program and also the peer mentors. FSP scholars are required to participate as members of the learning community their first year at Texas A\&M University and have the opportunity in their second, third, and fourth years to apply to serve as peer mentors for subsequent groups of program participants. Becoming a FSP peer mentor means that the undergraduate is accepting responsibility and making a commitment to their mentees. Peer mentors receive approximately one to three hours of training a month for their role. Topics of this training may include specific skills like suicide prevention awareness, bystander intervention, and how to be an ally, or the training may also consist of being informed about resources on campus and involve other leadership content. As part of the peer mentor experience, peer mentors meet weekly as a group with the full group of mentees in a class format. During these weekly class meetings, peer mentors take turns leading the meetings and discussing curriculum with the mentees. Examples of curriculum presented during the class meetings by the peer mentors includes time management skills, study skills, issues related to being a first-generation college student, changing majors, money management, and overall student health and wellness topics. Peer mentors meet with a program coordinator prior to presenting in class to ensure they are prepared to present to the mentees each week.

\section{Purpose of the Study}

The purpose of this study was to better understand and describe how students who are serving as FSP peer mentors perceive their development of leadership throughout the experience of serving as a peer mentor. This should be important to leadership educators as they consider how to structure their programs and experiences to allow for meaningful and optimal leadership growth of students.

\section{Methodology}

In this study, we used a basic qualitative study design (Merriam \& Tisdell, 2015). Basic qualitative research can be used to understand how people interpret their experiences to make meaning of a phenomenon in which they are involved (Merriam \& Tisdell, 2015).

Participants

Data for this study were obtained from college students serving as mentors to college peers. A purposive sample (Fraenkel et al., 2012) included students participating as FSP mentors for [University Program] Scholars at Texas A\&M University in the Fall 2015 semester. There were 47 peer mentors who 
had the potential to be included in this study. Some were in their first year of mentoring (FYM) and others were returning mentors (RM) in their second year of serving as a peer mentor. Of the 47 peer mentors $(N=47), 33(n=33)$ participated in this study (17 First year Mentors and 16 Returning Mentors).

All peer mentors in attendance at the October 2015 FSP Mentor Training were asked to participate in the study. Monthly peer mentor meetings serve as an opportunity for formal leadership education or professional development for all FSP peer mentors. At the October meeting, peer mentors completed a reflection about their personal best leadership experience as a peer mentor in the FSP. The October meeting was chosen as it provided a chance for leaders of the FSP to gain a snapshot of how the FYM defined their leadership and provide some areas of growth for these FYMs. The RM would have had more than a year of experience as a peer mentor, so it allowed for them to reflect and document their leadership growth over that year. The activity was completed in the lecture hall where each monthly mentor training took place. This allowed for timely collection of data with little to no disruption to the routine of FSP or its mentors. In order to ensure anonymity, the names of participants were deleted after collection and coded using a numerical and categorical system. Returning mentors were labeled RM, followed by a number between 1 and 16 . Firstyear mentors were coded FYM, followed by a number between 1 and 18 .

Access to this sample was gained by one of the researchers having served the FSP as a paid graduate assistant for one and a half years. During this time, the researcher was actively engaged in the daily dealings of the learning community. Having supervised four groups of four mentors as they navigated the duties and tasks of their mentorship, the researcher noticed the growth and development of these undergraduate mentors and proceeded to obtain permission from the learning community's director to include these students in this study.
Data Collection and Analysis

Content analysis was used as the methodological frame to examine the impact of serving as a peer mentor on leadership development (Fraenkel \& Wallen, 2009). Content analysis refers to analyzing communications, searching for emerging themes, and seeking to understand the significance of reoccurring phrases or other commonalties (Bryman, 2012). Content analysis provides numerous advantages relevant to leadership researchers (Insch et al., 1997). Deductive content analysis involves analyzing data according to an existing framework (Patton, 2002). We used the five practices (Kouzes \& Posner, 1987, 2002) as the basis of previous knowledge to conduct a deductive content analysis (Potter \& LevineDonnerstein, 1999).

There are three main phases of deductive content analysis: preparation, organization, and reporting of results (Elo et al., 2014). The preparation phase of deductive content analysis "consists of collecting suitable data from content analysis, making sense of the data, and selecting the unit of analysis" (Elo et al., 2014 , p. 2). To begin, we conducted "a review of the literature for relevant theory and previous research as the definition of research questions and contracts" (Insch et al., 1997). Based on this review of literature, we decided to examine leadership development in terms of transformational leadership, as operationalized by the five practices (Kouzes \& Posner, 1987, 2002). To best capture these "constructs of interest" (Insch et al., 1997), we concluded that the most suitable source of data were the written reflections of peer mentors about their personal best leadership experience and the reflections about their highest scored practice on the SLPI.

As part of the reflection, participants were asked to describe the leadership experience, including when it happened, how long, their role in it, their feelings before and after, whether or not they initiated it, and the results of the experience. Guided questions, including reporting their SLPI score, were used to enable participants to reflect on specific items. Participants were asked to summarize the five to 
seven most important actions they took as a leader to make a difference. The final part of the reflection asked participants to list three to five major lessons learned about leadership from their personal best leadership experience as a peer mentor.

Participants had previously completed the SLPI. Scores on the SLPI were not statistically analyzed and used as data in this study. Instead, the mentors were asked to self-report their highest scored leadership practice from their SLPI score as part of the reflection process to be used as a point of comparison for examining the prevalence of that practice within their reflections.

Also within the preparation phase of the deductive content analysis, we selected word sense or phrase as the suitable unit of analysis (Elo et al., 2014; Insch et al., 1997). Word sense or phase is a common unit of analysis that is "large enough to be considered as whole, but small enough to be a relevant meaning during the analysis process" (Elo et al., 2014, p. 5).

The second phase of deductive content analysis involves reviewing the data against the existing frame, which is the five practices model in this study (Kouzes \& Posner, 1987, 2002). Each personal best reflection was reviewed, analyzed, and coded against the pre-identified categories. Each unit of analysis was analyzed for evidence of each of the five practices (Kouzes \& Posner, 2018). When coding each unit of analysis, single classification, in which each unit was coded to the practice it "best fits" (Insch et al., 1997), was used. Single classification, as compared to multiple classification where each unit of analysis could be coded within more than one of the five practices, is recommended (Weber, 1990). Because we were using deductive content analysis, an assumed category scheme was used (Insch et al., 1997). Each of the five practices contains two framing commitments that operationalizes each of the practices. Researchers utilized the descriptions of these framing commitments when analyzing for evidence of the five practices and best fit. For example, the practice of enabling others to act has a commitment of 1) strengthening others by increasing confidence and competence and 2) fostering collaboration by building trust and facilitating relationships. When coding for this practice, researchers specifically looked for evidence of when the peer mentor did either of these two commitments. In cases where a peer mentor's description may have appeared to fit into multiple categories, the researchers gained clarification by discussing with other researchers and coming to a consensus about where it best fit. All researchers were very familiar with the five practices framework having prior experience in teaching these concepts. It should be noted that participants' reflections included multiple units of analysis. Referencing one practice within one unit of analysis did not preclude another practice being referenced in another unit of analysis. In other words, it was possible for different units of analysis within the same reflection to reference different practices.

Data were coded for both manifest and latent content. Manifest content is the surface level content and latent content is the underlying meaning of the content (Potter \& Levine-Donnerstein, 1999). More specifically, "Manifest content analysis looks at the most obvious and straightforward meanings of a text...whereas latent content analysis ferrets out a text's subtler meanings" (Ahuvia, 2001, p. 144). Both manifest and latent meaning require interpreting meanings (Ahuvia, 2001). Manifest content occurred when participant reflections included words that matched or were similar in meaning to the framing commitments of each leadership practice. Latent content occurred when the researchers had to infer subtler meaning by interpreting the words used by the participant as having the same meaning as the commitments of the five practices. For example, one participant's reflection stated, "I would ask questions that built on top of one another and got the students to start teaching themselves." We coded this as enable others to act because the peer mentor was attempting to increase their mentees' selfdetermination. Coding data against the predefined categories of the five practices (Kouzes \& Posner, 1987, 2002) increases the internal validity of the 
findings (Seuring \& Gold, 2012).

The final phase of deductive content analysis, the reporting phase, is the phase in which "results are described by the content of the categories describing the phenomenon using a selected approach" (Elo et al., 2014 p. 2). In this phase, we described how peer mentors within the FSP perceive the impact of their peer mentor experience on their leadership development. Through the deductive content analysis process, it was possible to break apart participants' reflections and reconfigure the data into the five practices (Kouzes \& Posner, 1987, 2002). There are two common methods of interpreting content analysis data: the use of frequencies and the percentage and/or proportion of particular occurrences to total occurrences, and the use of codes and themes to help organize the content and arrive at a narrative description of the findings (Fraenkel et al., 2012). Both methods were used in this study.

Research Quality and Trustworthiness

To establish trustworthiness, Lincoln and Guba's (1985) concepts of transferability, dependability, credibility, and confirmability were used in the process of data collection and analysis. Credibility in qualitative research is addressed by assessing how the findings from the study line up with what is actually taking place (Merriam \& Tisdell, 2015). Qualitative research does not take place in a vacuum, and is constantly changing and evolving. In order to capture and present a holistic view of what the researcher has observed, prolonged engagement was used to assist the creation of credibility (Lincoln \& Guba, 1985). One member of our research team served the FSP Learning Community for one and half years as a graduate assistant and worked closely with FSP mentors and staff on a daily basis. As a graduate assistant, she worked one-on-one with mentors, assisted in development and implementation of training sessions, and was involved in the daily functions of the FSP learning community. She was familiar with program norms and able to present results that are representative and congruent with their experiences in the learning community. Peer debriefing with all researchers in this study (Lincoln \& Guba, 1985) was also used to enhance the credibility of this study. Peers were asked to review samples of raw data to ensure that the researchers' thought process was at a place where data and categories were representative of the raw data.

To enhance transferability, we provided extensive background knowledge on the learning community and the student population that it serves as well as described our access and relationship to the population. Dependability and confirmability were established through the use of an audit trail, researcher-kept reflexive journals, and peer debriefing (Lincoln \& Guba, 1985). Data were coded FYM 1-FYM17 for First Year Mentors, and RM 1-RM 16 for Returning Mentors (denoting that the mentor has served more than one year as a FSP Mentor). Data were coded before the analysis began to ensure the confidentiality of the students; these data codes are included in the quotations to produce an audit trail.

\section{Findings}

Findings are presented based on the five practices of exemplary leaders. While we discuss each practice separately, we acknowledge these behaviors can cut across multiple practices and may not always be carried out by leaders in isolation. We also crossanalyzed the frequency of times an individual's reflection was coded for each practice with their selfreported highest scored practice on the SLPI, and this is reported in this findings section.

\section{Enable Others to Act}

Of the 33 peer mentors, $24(72.72 \%)$ referenced the enable others to act practice within the description of their personal best leadership experience. The mentors whose personal best leadership experiences fell within the practice of enabling others to act referenced situations where collaboration and teamwork needed to be improved upon, or situations involving assisting a freshmen or group of freshmen in feeling welcomed and included in 
campus culture of Texas A\&M University and the FSP Learning community. Many of the mentors reflected upon a time when they found ways to boost their own confidence or the confidence of someone else by helping to increase competence and creating a sense of accomplishment.

FYM1 described enabling others to act within the context of an FSP session and suggested the quiet mentees take on the jobs that the extroverted ones would normally take. RM8 reflected on a time they worked to build confidence in their mentees by having the mentees participate in the check-in process during an all-day student-led community service project. This allowed mentees to feel a sense of ownership in their volunteer process as well as gave them the chance to see a new process through for themselves.

RM12 told us how they go about engaging others and inviting and welcoming them to become an active part of the situations that mentees may find themselves in. RM13 also described how they coached mentees to become engaged by asking questions that built on top of one another and eventually got students to teach themselves. These mentors enabled their mentees to take their learning process into their own hands and helped them gain the confidence in their own abilities.

FYM2 and FYM3 described their personal best leadership experience as a time they assisted mentees who were struggling in their first year of college. These mentors took time to first get to know these mentees on a personal level and then assisted the mentees in finding the appropriate avenues for addressing the issues. FYM2 assisted a mentee who was considering dropping a course. FYM2 ensured that the mentee knew the correct people to talk to and what that process would look like. FYM3 enabled their mentee through motivation when one of her mentees was not sure if they wanted to continue their education at Texas A\&M University.

FYM13 and FYM15 provided a look at the challenges of mentoring in the FSP Learning Community. FYM13 stated their leadership style has been enacted by "guiding my mentees through any hardships they are going through." FYM13 also discussed working with their mentees through situations ranging from academic to personal and from short-term solutions to further planning. As a mentor, FYM13 demonstrated the understanding that a mentor is there for assistance and is not a "decision engine." FYM13 and FYM15 are enabling mentees to take action by sharing with them information and options, but not providing the answers or solutions that mentees should be learning to find for themselves.

Model the Way

Of the 33 peer mentors, 15 (45.45\%) referenced a model the way practice in describing their personal best leadership experience. When it comes to being role models and setting examples, FSP mentors have a plethora of experience. These undergraduate students lead large group activities, facilitate small group discussions, and act as examples of experienced college students. Many have also previously participated in FSP as freshmen and have seen mentors in action. These mentors strive to set positive examples for not only their mentees they work most closely with but for the freshmen of the FSP Learning Community as a whole.

These mentors have been through many of the same situations as, or in situations similar enough that they are able to relate to, their mentees. FYM3 was able to use their experiences as a first-generation college student to help their mentee see that as a first-generation college student, they were not alone. FYM3 shared their experience and offered to give the mentee any assistance they may need help with to find a resource or need someone to listen. FYM3 and this particular mentee discussed the difficulty of college and the worth of sticking it out. FYM12 also shared their experience with mentees from early in the academic year: "At first, the girls were shy and scared to share, so I tried to be extra-outgoing and told a few embarrassing stories about my first week of college to make them at ease and comfortable." This mentor shared values and encouraged her mentees to begin to open up by being the first to 
share and attempt to build connections within their group. RM15 shared that "Passion and love for what [you're] doing are key to moving people to get the job done."

Mentors also discussed having modeled the way for mentees when the mentors were unaware of their impact. RM10 reflected that their personal best leadership experience revolved around two of their mentees from the previous year deciding to apply to become FSP mentors, stating that "you inspire/lead without actually knowing it." RM1 also reflected on a mentee deciding to apply to serve as a FSP mentor because they had observed the impact their mentor had on them and wanted to impact another freshman in the same way.

Mentors have the ability to model the way in FSP in more ways than being good role models for freshmen. FSP mentors work closely with full-time staff to ensure that the FSP freshmen are receiving the assistance and attention that is needed. FSP mentors have the opportunity to lead team meetings and are encouraged to speak openly with their supervisors. RM5 reflected on how their willingness to model the way during their weekly mentor meetings made a very large impact on the productivity of their meetings: "Honestly, after setting an example I felt like the meetings now have better flow \& mentor/coordinator is more prepared." RM5 went on to explain the actions they took in order to make this difference and model the way. These actions included being there on time, having IFS prep ready a day before the meeting, having the activities pulled out on their laptop before the meeting \& having questions for facilitation. FSP mentors strive to set appropriate examples for their mentees and clarify values (those of the organization and the university).

Inspire a Shared Vision

Of the 33 peer mentors, 13 (39.39\%) referenced the practice of inspire a shared vision within their personal best leadership experience. While mentors are working with such a wide variety of students, each with their own goals, creating a shared vision may seem daunting. RM7 provided advice on how they tackled the task of inspiring a shared vision. They advise that you not get discouraged when there are those who may not be as motivated as you, and they share that each person is different. Mentors who have been identified as having used the practice of inspire a shared vision reflected on providing encouragement (RM16, FYM4, FYM17, and FYM18), reminding others of a common goal (RM2, RM7, RM11, FYM7, FYM10, and FYM12), motivation (FYM9 and FYM11), and the transition from mentee to mentor (RM10 and RM11).

Motivation for their vision is something that all students could use as they transition to university life, including having mentors provides mentees with a source of excitement toward their vision outside of their family and friend structures. FYM17 assisted a mentee that was unsure of their current major and was seeking advice on how to change it. FYM17 took the time to speak with the mentee and they wrote out a list together of steps they should take. FYM17 assisted their mentee in a time of uncertainty by letting the mentee describe what it is they wanted and allowing FYM17 to explain the process of working toward the desired outcome. Other times, it is not the mentees who are the only ones in need of a shared vision. In order for an FSP session to operate smoothly, mentors must effectively communicate within their team and with their FSP coordinator. RM16 addressed this when they reflected upon a time they encouraged open communication in their team in the context of a planning session for an InFSP Session. In this case, RM16 asked all members to speak freely on certain issues that were affecting the unity and productivity of the group. This allowed all mentors and coordinators involved to share their vision for the IFS. FYM9 also addressed inspiring a shared vision within their mentor team: "In order to keep the other mentors from losing interest I made sure to ask for their input in order to be sure that they felt they were being led and not being ordered to do anything." FYM9 discussed keeping mentors engaged during an In-FSP Session, and the importance of asking for input from teammates in order to keep all teammates engaged and working toward the 
same goal. RM11 also discussed the importance of collaboration in terms of inspiring a shared vision: "A good leader not only helps others by guiding, they also learn from those around them."

Part of inspiring a shared vision is reminding others of the common goals. RM7 offered the advice that "you can only motivate people so much, but if you are going for a common goal...gathering people and making things happen will pay itself." In regards to keeping common goals in mind, RM11 shared that they applied to become a mentor because their mentor did not meet expectations. RM11 wanted to do what they could to ensure that other freshmen had a reliable mentor. RM11 inspired a shared vision by helping their mentees remember their goals and what they hoped to achieve in college.

Inspiring a shared vision can be difficult, especially when the goal is continued buy-in and action. Mentors take pride in the work that they do, and mentors feel that they have inspired mentees when their mentees apply to become mentors. RM10 wrote that they had not realized the impact they had had on their mentees. After spending a semester with their mentees, RM10 wrote that their mentees said, "...they owed FSP a lot and the mentors as well." RM10 shows that FSP mentors have more pull with their mentees than they may realize. Mentors have the power to inspire others to carry on what previous FSP mentors have begun.

\section{Challenge the Process}

Of the 33 peer mentors, nine (27.27\%) referenced a challenge the process practice in describing their personal best leadership experience. FSP mentors are given a great deal of responsibility and a certain degree of freedom with their mentorship. They are able to decide how they can best serve their mentees, they are able to adapt lesson plans to accommodate the freshmen in seminars they lead, and they are encouraged to reach beyond their own comfort zones to help others grow. Being a mentor, at times, is about challenging what has been done in the past to create a better process for the learning community.
Mentors who were identified as having used this practice in their personal best leadership experience discussed times that they changed a process within the FSP Learning Community. For example, when FYM4 decided the way an activity was to be presented in an In-FSP Session would not benefit their students in the way it was intended to, they changed the activity completely. FYM4 was able to change the activity and conduct the In-FSP Session in a way that they saw fit for where their students were at. In doing this, FYM4 says that students were able to engage and participate in a level that RM4 had not seen with that group of freshmen. FYM18 also reflected on a time they saw room for improvement in an In-FSP Session lesson. They took the initiative to adapt an activity to better suit the needs of their freshmen. RM4 provided a slightly different take on adapting In-FSP Session lessons and reflects on a time they were able to challenge the process in a very discrete way. As a returning mentor, they had the opportunity to assist a first year mentor developing their debriefing skills while ensuring the freshmen were understanding what was being asked of them. RM4 reflected on their personal development as a mentor and how they were seeking ways to help others: "I took the initiative in helping paraphrase the questions being asked, but stepped back when I saw the mentor getting the hang of it" (RM4). RM4 saw a fellow mentor struggling to facilitate part of the lesson and found a way to assist that would not be seen as interfering with a teammates' role for that lesson.

There are times when subtle changes to a lesson plan may not bring about the change that a mentor is looking for in the In-FSP Session structure. Sometimes the change must begin within the mentor team itself, and that is what FYM10 was referring to when they stated, "I made a decision to change the status quo of how our In-FSP Session normally worked and took a risk [with] how everything would be set up." According to FYM10, the process that needed to be changed was how the mentors worked as a team. RM9 took a look inside themselves to find room for improvement and reflected upon their first year as a FSP mentor 
and how they plan to "find a better approach on how to build relationships with [mentees]." Constructive feedback is a valuable learning tool. FSP mentors are constantly seeking feedback and looking for innovative ways to engage with their mentees. RM5 reported having provided feedback to new mentors when they saw room for improvement or wanted to let the new mentor know they were doing a good job.

Encourage the Heart

Of the 33 peer mentors, seven (21.21\%) referenced the encourage the heart practice in describing their personal best leadership experience. When a leader encourages the heart, they recognize and appreciate the personal contributions of their team members. By celebrating and encouraging others, leaders help keep their followers motivated and dedicated to their goal (Kouzes \& Posner, 2018). Common occurrences in reflections were letting mentees know they were not in their situations alone and encouragement and/or affirmation of a job well done. These actions are positive reinforcement for freshmen and fellow mentors alike.

FYM8 reflected on a time where they encouraged a mentee encountering academic struggles: "...l let him know that even though he's hit some bumps in the road, that failures are just learning experiences." FYM12 reflected that they were "able to facilitate discussions about their fears, excitements, and first weeks while sharing good advice." These mentors were able to show their mentees they were not alone. The sharing of experiences and feelings assists in creating an environment in which all involved may feel comfortable encouraging their peers.

When mentors consider encouragement, some also remember that recognizing a job well done can be just as effective as public praise. FYM17 reflected on the value in recognizing a job well done and also stated, "Experience is a great teacher, patience and understanding go a long way, and encouragement increases likelihood of success."

RM5 spoke of providing constructive feedback in areas that need improvement but also briefly discussed the importance of acknowledging when things are going well. RM15 reflected, "When you get people moving and assigning them tasks they may come up with new ideas, encourage those ideas and you start seeing wonderful results."

SLPI Scores and Frequency of Practice

Participants self-reported their highest scored practice from the SLPI within their reflection. We tabulated each participants' highest scored practice along with the number of times a practice was identified within their personal best leadership reflections. Of the 33 participants, 19 (57.5\%) of them referenced their highest scored practice more than the other practices.

\section{Conclusions \& Recommendations}

The purpose of this study was to understand how undergraduate students serving as peer mentors to college freshmen perceived their mentorship experience as contributing to their overall leadership development. We believe the Kouzes and Posner (2018) model of the five leadership practices has utility in understanding peer mentors' experiences and how they develop as leaders. Each students' reflection showed that FSP mentors believe their mentorship is allowing them to utilize and enhance these five leadership practices. In all but one reflection, mentor responses exhibited evidence of at least one of the five practices being used during their personal best leadership experience within the context of FSP. A majority of students (19 of 33, $57.5 \%)$ referenced their self-reported highest scored practice within their reflections more than the other practices. This further validates that students were utilizing this practice as a peer mentor and increases the likelihood of being seen as an effective leader by their peers (Posner, 2012).

FSP mentors demonstrated the five leadership practices during their time as FSP mentors. Based on findings from this study, mentors took time to get to know the needs of their mentees and what can be done to meet those needs. Mentors who 
reported their highest scored practice as model the way described setting an example and sharing past experiences to help others avoid the same mistakes. As for goal setting and motivation, mentors engage in leadership practices, especially in enabling others to act, inspiring a shared vision, and encouraging the heart. Mentors took the time to get to know each of their mentees on a personal level as well as in group settings. They were getting to know what motivated mentees to continue in school, reach goals, and strive for success. Mentors strived to encourage mentees to be more and do more than they thought possible. Mentors provided a source of encouragement for students, as made evident by their reflections pertaining to encouraging mentees who were uncertain in their decision to attend Texas A\&M University and then encouraging mentees to participate in FSP and campus activities. It is encouraging that all five of the practices were demonstrated by the peer mentors, as this implies that peer mentors are developing their leadership through the experience of being a peer mentor. And, since Posner (2012) noted the more students have opportunities to demonstrate the five practices, the more effective they are viewed, we can conclude that peer mentors are becoming more effective leaders through their experience as a peer mentor.

The practice of enable others to act was the most prevalent practice articulated by the peer mentors in their personal best leadership experience. Encourage the heart was the least articulated practice described by the peer mentors. The practice of encourage the heart is mostly about building up others and celebrating their successes and involves more relationship-focused behaviors. Enable others to act is also focused on relationships, but has more of an emphasis on getting others to complete something and can be a little more task-focused. While it may appear from the findings that peer mentors have more opportunities to demonstrate the practice of enable others to act, it is possible that the guiding questions asked within the reflections about the peer mentors' personal best experience skewed their answers to concentrate more on the professional components (or task behaviors) of their peer mentor experience and less on the personal aspects of the experience (or relationship components). It is also possible that the timing of data collection (at the October meeting) made it difficult for FYMs to consider their actions related to encourage the heart, especially in celebrating the successes of their mentees, within their personal best experience.

Based on the findings from this study, it is evident that the peer mentors not only demonstrate their leadership behaviors through the one-on-one meetings with their mentee, but also in their weekly training sessions and meetings with their peer groups. In this FSP, we can conclude that the peer mentoring experience is more than just the oneon-one interactions with mentees. This could have impacts for the field of peer mentoring in recognizing it as a process and not simply about a relationship between two individuals.

Recommendations for Practice

Based on the findings of this study, it appears that the FSP Learning Community provided a context for undergraduate students to utilize and engage in leadership practices and competencies within their roles as mentors. However, more could be done to cultivate the leadership development of the peer mentors. Though a session of training for the peer mentors was devoted to talking about the five leadership practices for this study, there was not an absolute focus on leadership education during the trainings for the peer mentors. As a result of this study, there has been a bigger emphasis on leadership training and helping the peer mentors recognize their leadership growth and development. It is recommended that the FSP strategically incorporate specific leadership training content and be intentional with including time for reflection about their leadership abilities into their training program for peer mentors. Peer mentors may not recognize the leadership skills and competencies they are developing through the experience unless it is articulated and shared with them. As another study has found, peer mentors need education and 
training to realize their development and growth in leadership (Lee et al., 2020).

Specifically, we observed some outcomes regarding how the peer mentors experienced each of the five practices through their work as a peer mentor. The FSP appears to impress upon its mentors the importance of modeling the way and enabling others to act. It is encouraging that the majority of mentors were able to describe experiences in which they used enabling others to act to help other first-generation students feel successful. Many mentors also reflected upon times when, even though other practices were being used, modeling the way was the practice that served as the foundation for many interactions. The FSP, in the interest of developing well rounded leaders, should begin to find ways to encourage mentors to encourage the heart more often. Based on reflections shared by mentors, this is a practice that was least referred to by the peer mentors. Peer mentors may simply not recognize they are demonstrating leadership by encouraging the heart. The FSP should recognize ways to emphasize the importance of encouraging the heart and how it influences their ability to be an effective leader.

\section{Recommendations for Further Research}

This study included mentors with varying levels of experience (First Year Mentors and Returning Mentors) for similar leadership development experiences with little regard to how the First Year Mentor responses differ from the Returning Mentor responses. Further research needs to be done on how longevity as a mentor may impact perceptions of leadership development in regards to the five practices of exemplary leadership. We employed content analysis, so we did not ask follow-up questions to the students after they submitted their reflections. Future studies should build upon this study by including methods that assess student responses as well as ask pertinent follow up questions.

In this study, because students did not know the terminology of the five practices prior to their reflection activity, the researchers had to interpret students' words to reveal what practices were evident in their reflections. A future study could examine congruence between what students label as a practice compared to the descriptions of the practice. This may enable leadership educators to be more intentional in helping peer mentors implement behaviors from all five leadership practices.

Another follow-up study might include a more holistic examination of all of the activities involved in the peer mentor experience and how the activities align with the five practices of exemplary leadership model. This study asked peer mentors to identify their personal best leadership experience as a peer mentor. It is possible that some activities that develop the peer mentors' leadership abilities were missed in the analysis. Identifying all activities that nurture leadership through other quantitative and qualitative designs would allow for the program coordinator to recognize where they should intentionally focus their efforts and design meaningful ways to engage students in developing as leaders through the peer mentor experience. 


\section{References}

Ahuvia, A. (2001). Traditional, interpretive, and reception based content analysis: Improving the ability of content analysis to address issues of pragmatic and theoretical concern. Social Indicators Research, 54(2), 139-172.

Astin, A. W., \& Astin, H. S. (2000). Leadership reconsidered: Engaging higher education in social change. W. K. Kellogg Foundation.

Barnes, S. R. (2014). Exploring the socially responsible leadership capacity of college student leaders who mentor [Unpublished master's thesis]. University of Nebraska-Lincoln.

Bower, A. M., \& Inkelas, K. K. (2010). Living-learning programs: One high-impact educational practice we know a lot about. Liberal Education, 96(2), 36-43.

Bryman, A. (2012). Social research methods (4th ed.). Oxford University Press.

Campbell, C. M., Smith, M., Dugan, J. P., \& Komives, S. R. (2012). Mentors and college student leadership outcomes: The importance of position and process. The Review of Higher Education, 35(4), 595-625.

Collins-Shapiro, C. (2006). Mentoring and leadership development. Leadership insights and application series \#21. National Clearinghouse for Leadership Programs.

Colvin, J. W., \& Ashman, M. (2010). Roles, risks, and benefits of peer mentoring relationships in higher education. Mentoring \& Tutoring: Partnership in Learning, 18(2), 121-134.

Connolly, S. (2017). The impact of peer mentoring on the mentors. Journal of Applied Research in Higher Education, 9(2), 255-266. https://doi.org/10.1108/JARHE-10-2015-0078

Council for the Advancement of Standards in Higher Education. (2015). CAS learning and development outcomes. In J. B. Wells (Ed.), CAS professional standards for higher education (9th ed.). Council for the Advancement of Standards in Higher Education.

Dugan, J. P., \& Komives, S. R. (2007). Developing leadership capacity in college students: Findings from a national study. A Report from the Multi-Institutional Study of Leadership. National Clearinghouse for Leadership Programs.

Dugan, J. P., \& Komives, S. R. (2010). Influences on college students' capacities for socially responsible leadership. Journal of College Student Development, 51(5), 525-549.

Elo, S., Kääriäinen, M., Kanste, O., Plkki, T., Utriainen, K., \& Kyngäs, H. (2014). Qualitative content analysis: A focus on trustworthiness. SAGE Open, 4(1), 1-10. https://doi.org/10.1177/2158244014522633

Fraenkel, J. R., \& Wallen, N. E. (2009). How to Design and Evaluate Research in Education (7th ed.). McGrawHill.

Fraenkel, J. R., Wallen, N. E., \& Hyun, H. H. (2012). How to Design and Evaluate Research in Education (8th ed.). McGraw-Hill.

Hastings, L. J., Griesen, J. V., Hoover, R. E., Creswell, J. W., \& Dlugosh, L. L. (2015). Generativity in college students: Comparing and explaining the impact of mentoring. Journal of College Student Development, 56(7), 651-669. 


\section{References}

Hastings, L. J., \& Sunderman, H. M. (2019). Generativity and socially responsible leadership among college student leaders who mentor. Journal of Leadership Education, 18(3), 1-14.

Insch, G. S., Moore, J. E.. \& Murphy, L. D. (1997). Content analysis in leadership research: Examples, procedures, and suggestions for future use. Leadership Quarterly, 8(1), 1-25.

Kouzes, J. M., \& Posner, B. Z. (1987). The leadership challenge: How to get extraordinary things done in organizations. Jossey-Bass.

Kouzes, J. M., \& Posner, B. Z. (2002). Leadership challenge (2nd ed.). Jossey-Bass.

Kouzes, J. M., \& Posner, B. Z. (2018). The student leadership challenge: Five practices for becoming an exemplary leader. (3rd ed.). Jossey-Bass.

Komives, S. R., \& Collins-Shapiro, C. (2006). The critical role of mentoring in leadership development. Concepts and Connections, 14(3), 9-11.

Komives, S. R., Owen, J. E., Longerbeam, S., Mainella, F. C., \& Osteen, L. (2005). Developing a leadership identity: A grounded theory. Journal of College Student Development, 46(6), 593-611. https://doi. org/10.1353/csd.2005.0061

Komives, S. R., Longerbeam, S. D., Mainella, F., Osteen, L., \& Owen, J. E. (2009). Leadership identity development: Challenges in applying a developmental model. Journal of Leadership Education, 8(1), 1147.

Lee, J., Sunderman, H., \& Hastings, L. (2020). The influence of being a mentor on leadership development: Recommendations for curricular and co-curricular experiences. Journal of Leadership Education,19(3), 44-60.

Lincoln, Y. S., \& Guba, E. G. (1985). Naturalistic inquiry. Sage.

Merriam, S. B., \& Tisdell, E. J. (2015). Qualitative research: A guide to design and implementation (4th ed.). John Wiley \& Sons.

Northouse, P. (2013). Leadership: Theory and Practice. (6th ed.). Sage.

Parks, S. D. (2000). Big questions, worthy dreams: Mentoring young adults in the search for meaning, purpose, and faith. Jossey-Bass.

Patton, M. Q. (2002). Qualitative research \& evaluation methods (3rd ed.). Sage.

Posner, B. Z. (2012). Effectively measuring student leadership. Administrative Sciences, 2(4), 221-234.

Potter, W., J., \& Levine-Donnerstein, D. (1999). Rethinking validity and reliability in content analysis. Journal of Applied Communication Research, 27(3), 258-284. https://doi.org/10.1080/00909889909365539

Rossi, A. S. (2001). Domains and dimensions of social responsibility: A sociodemographic profile. In A. S. Rossi (Ed.), Caring and doing for others: Social responsibility in the domains of family, work, and community (pp. 97-134). University of Chicago Press. 


\section{References}

Seuring, S., \& Gold, S. (2012). Conducting content-analysis based literature reviews in supply chain management. Supply Chain Management, 17(5), 544-555. https://doi.org/10.1108/13598541211258609

Texas A\&M University. (n.d.). What is First Generation? Office for Student Success. Retrieved July 29, 2020, from https://studentsuccess.tamu.edu

Weber, R. P. (1990). Basic content analysis (2nd ed.). Sage. 